\title{
Abnormal Serum Factor in Patients with Cystic Fibrosis of the Pancreas
}

\author{
A.Spock ${ }^{[14]}$, H.M.C. Heick, H. Cress and W.S. Logan \\ Department of Pediatrics, Duke University Medical Center, Durham, North Carolina, USA
}

Extract

Serum from patients with cystic fibrosis of the pancreas (CFP) was found to disorganize the ciliary rhythm in explants of respiratory epithelium. This serum factor was present in all 75 patients with CFP and absent from the serum of 75 other patients having a variety of diseases with clinical features similar to those seen in CFP.

The bio-assay method to detect the disorganized ciliary beat was performed in the following manner. Specimens of rabbit tracheal mucosa were placed and maintained in tissue culture flasks using standard tissue culture technique. After 4-6 days of incubation, specimens with beating cilia were removed from the flasks, placed on glass slides, exposed to a drop of test serum, covered with a sealed coverslip, and observed at room temperature with a magnification of 550 using phase contract illumination. A disorganized beat was usually observed within 5-10 minutes and persisted for a period of up to one hour.

The serum factor was found to be heat labile, nondialysable, and precipitated with the euglobulins. Chromatographic examination of serum from a patient with CFP on a column of Sephadex G-200 showed that the serum factor was eluted with the macroglobulin fraction as well as between the gamma globulin and albumin peaks.

The serum factor was also detected in the parents of children with cystic fibrosis; however, the concentration of the factor appeared lower. The native sera from parents produced a disorganized beat in 7 of 25 cases. Upon concentrating the euglobulin fraction 2.5:1, the factor was detected in the remaining 18 sera. Similar concentration of sera from control-patients resulted in only one positive reaction in the 25 sera tested. In addition, a ten-fold concentration of euglobulin from normal controls failed to disorganize the ciliary beat.

\section{Speculation}

Although the mode of action of the serum factor has not been determined, the macromolecules in the serum may alter transport of electrolytes, thereby producing changes in the action potential within the cell and resulting in a disorganized ciliary beat.|This postulate may have also some relation to the pathogenesis of the disease in view of the recent observation by MANGos and MaShERRY [7] that saliva of patients with CFP inhibits sodium transport. 
Introduction

In the course of studying ciliary motility, we observed that sera from patients with cystic fibrosis of the pancreas (GFP) produced a disorganized ciliary beat when added to explants of tracheal mucosa. A similar effect was noted when sera from parents of children with CFP were examined. This observation led to the utilization of this procedure for detecting individuals with active cystic fibrosis of the pancreas and for identifying heterozygous carriers of the disease.

The purpose of this paper is to describe the techniques utilized to observe this disorganized ciliary beat and to report preliminary studies on the properties of the serum factor responsible for this phenomenon.

\section{Materials and Methods}

The 75 patients with GFP in this study attended the Cystic Fibrosis Clinic of the Department of Pediatrics at Duke University Medical Center. All but one of the patients were white and the ages ranged from 10 days to 21 years. The diagnosis was confirmed in all patients by the clinical history and the presence of an elevated concentration of chloride in the sweat [4]. Seventyfive subjects (patient controls) were also studied; their ages varied from one to 50 years. The diagnoses of control patients included agammaglobulinemia, bronchial asthma, bronchiectasis, celiac syndrome, cirrhosis of the liver, diabetes mellitus, eczema, hayfever, leukemia, pancreatitis, recurrent pneumonia, rheumatoid arthritis, and sarcoidosis. A few who were studied had no disease. In addition, the sera from 25 parents (12 males and 13 females) of children with CFP and 25 asymptomatic adult volunteers were studied.

Either heparinized, citrated, or clotted blood was obtained; the sera were stored at $-4^{\circ}$ until used. Samples could be thawed and frozen several times and stored for periods of three years without obvious change in activity.

The bio-assay was performed in the following manner. Tracheal epithelium specimens were taken from normal New Zealand white rabbits killed by injection of air into the ear vein. The trachea was quickly exposed and the mucosa dissected from the underlying tissue. Pieces of mucosa were minced into 1-2 $\mathrm{mm}$ segments; 10-20 fragments suspended in 2 to $3 \mathrm{ml}$ of medium were placed into $30 \mathrm{ml}$ 'Falcon' plastic flasks and incubated at $37^{\circ}$. Standard tissue culture techniques were employed using $80 \%$ medium 199 and $20 \%$ rabbit serum with penicillin (50 units per $\mathrm{ml}$ ) and streptomycin (50 $\mu \mathrm{g}$ per $\mathrm{ml}$ ). The $\mathrm{pH}$ was adjusted to 7.4. Specimens with beating cilia were removed from flasks after 4-6 days of incubation, placed on glass
Table I. Dyskinetic ciliary beat noted with sera and euglobulin

\begin{tabular}{lcc}
\hline Test material & \multicolumn{2}{c}{ No. of cases } \\
& Total & $\begin{array}{l}\text { Diskinetic } \\
\text { beat }\end{array}$ \\
\hline Sera of GFP patients & 75 & 75 \\
Sera of control patients & 75 & 0 \\
Sera of CFP parents & 25 & 7 \\
$\begin{array}{lcc}\text { Euglobulin of GFP parents with } \\
\text { nonreactive sera }\end{array}$ & 18 & 18 \\
$\begin{array}{l}\text { Euglobulin of asymptomatic } \\
\text { adults }\end{array}$ & 25 & 1 \\
\hline
\end{tabular}

Table II. Comparison of sweat chloride levels and dyskinetic ciliary beat in parents of children with CFP

\begin{tabular}{lcccc}
\hline Parent group & $\begin{array}{l}\text { Num- } \\
\text { ber }\end{array}$ & Mean & Range & $\begin{array}{l}\text { Chloride concen- } \\
\text { tration }-\mathrm{mEq} / \mathrm{l} \\
\text { deviation }\end{array}$ \\
\hline & & & & \\
\hline $\begin{array}{l}\text { Dyskinesis with } \\
\text { sera }\end{array}$ & 7 & 45 & $30-68$ & 12 \\
$\begin{array}{l}\text { Dyskinesis with } \\
\text { euglobulin }\end{array}$ & 18 & 35 & $20-58$ & 11 \\
Entire group & 25 & 37 & $20-68$ & 11 \\
\hline
\end{tabular}

slides, exposed to a drop of test serum and covered with a coverslip. The preparation was sealed with petrolatum. Observations were made at room temperature $\left(23^{\circ}\right.$ to $\left.25^{\circ}\right)$ with a magnification of 550 using phase contrast illumination.

Serum $(3.5 \mathrm{ml})$ was fractionated by gel filtration on a column of Sephadex G-200, $4.2 \times 110 \mathrm{~cm}$. The chromatogram was developed with a solution of 0.15 molar sodium chloride buffered with 0.01 molar sodium phosphate at $\mathrm{pH}$ 7.4. This solution was used in all the experiments requiring buffered saline. Samples, $5 \mathrm{ml}$ in volume, were collected and the optical density of each was determined at $280 \mathrm{~m} \mu$. The effluent was divided into five fractions (fig. 1) and each fraction was concentrated to $3 \mathrm{ml}$ by ultrafiltration through dialysis casing in vacuum. Fractions 1, 3 and 5 represent the macroglobulins, gamma globulin and albumin respectively, while fractions 2 and 4 are the intervening fractions between the main peaks.

Euglobulin preparations were made by adding 10 volumes of water saturated with carbon dioxide at $4^{\circ}$ to one volume of serum. The precipitate was removed by centrifugation and redissolved in a volume of buffer- 
ed saline equal to the original volume of serum. The supernatant was lyopholized and the protein redissolved in an equivalent volume of buffered saline.

Concentrated euglobulin preparations were made from the sera of the parents and of the asymptomatic volunteers by dissolving the euglobulin precipitate from $2.5 \mathrm{ml}$ of serum in $1 \mathrm{ml}$ of buffered saline. Preparations similarly concentrated were used in the family study. A number of the sera and concentrated euglobulin preparations from patients as well as from known normal individuals were assayed at the same time that the sera of the family members were being examined. The samples were numbered and their identity was not known to the observer performing the assay.

\section{Results}

Under conditions of the present assay, cilia beat with rhythmic unison at a rate of approximately 800 times per minute thereby creating a wave motion. This motion is similar to the movement produced by wind in a wheat field. This movement is represented diagrammatically in figure 2A. In contrast, when serum from a patient with CFP was applied to a specimen an asynchronous beat was observed within 5-10 minutes and persisted for a period up to 1 hour (fig. 2B). With longer periods of observation, the border became obscured with desquamated cells and was no longer suitable for study. Such an asynchronous beat was produced by the sera of all 75 patients tested. In contrast, sera from the 75 control patients produced no alterations in the ciliary rhythm (table I).

When the serum proteins were divided into the euglobulin and pseudoglobulin fractions, the capacity to produce the asynchronous beat was found to reside only in the euglobulin (water insoluble) fraction. The activity was not lost by dialysis against saline but was destroyed by heating the serum at $100^{\circ}$ for 1 minute.

In figure 1 is shown a chromatogram of the serum proteins from a patient with GFP resolved on Sephadex G-200. When the chromatographic fractions were tested againșt tracheal epithelium, the asynchronous beat was produced only by fractions 1 and 4 . Fraction 1 appeared more active than fraction 4 . These results indicate that the activity is associated with two molecular species. The major component is excluded from the gel and thus is associated with serum proteins having a molecular weight of at least 200,000 while the minor component is associated with the molecular species eluted from the column between albumin (Mol. wt. 60,000) and gamma globulin (Mol. wt. 156,000).

In order to determine if the abnormal serum factor is also present in the presumed heterozygotes, sera from

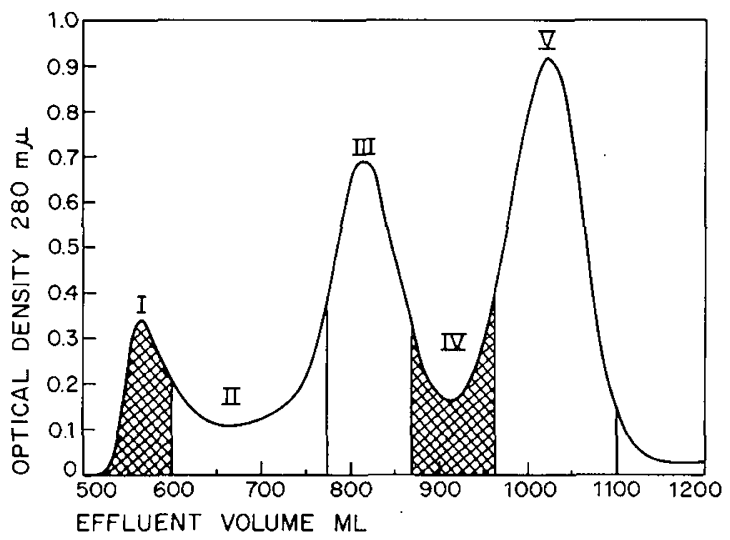

Fig.1. Ghromatogram on Sephadex G-200 of serum from patients with CFP. Vertical lines indicate specific fractions; diagonal lines indicate fractions where activity was found.

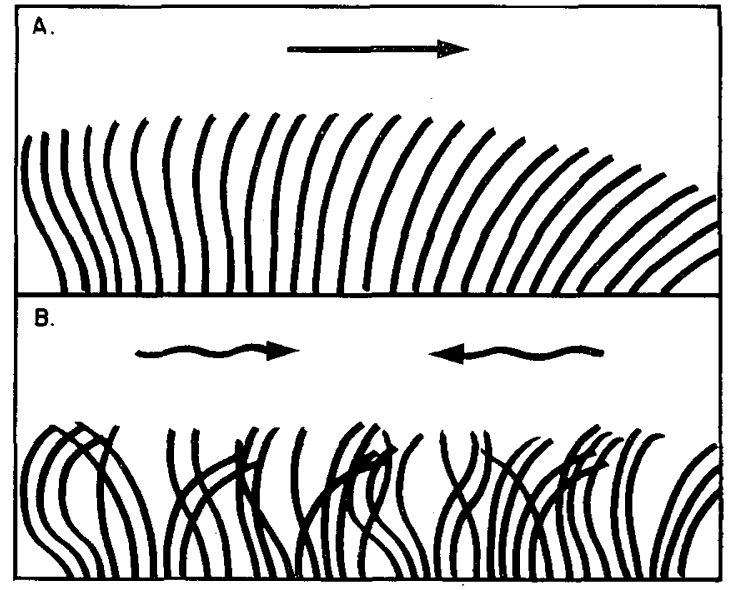

Fig. 2 A. Normal rhythmic ciliary beat; 2 B. disorganized ciliary beat produced by serum of CFP patient.

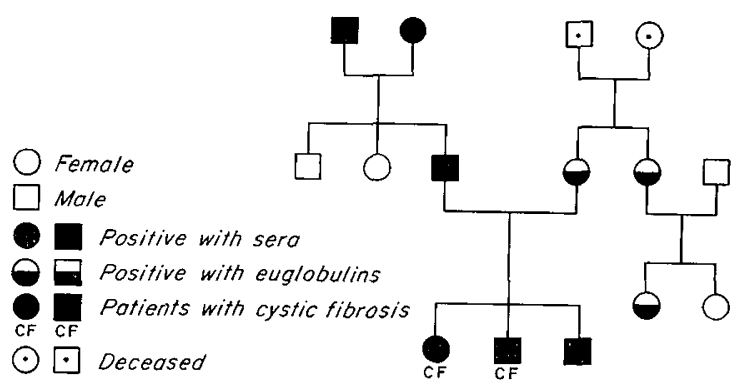

Fig. 3. Pedigree of family with GFP. 
25 parents of patients with GFP were tested. Sera from 7 of the parents were capable of altering the ciliary rhythm (table I). Whole sera from 18 parents failed to produce an asynchronous beat but the concentrated euglobulin fractions obtained from these sera were all capable of disorganizing the ciliary rhythm. On the other hand, in only one individual out of 25 adult volunteers with no family history of CFP did the concentrated euglobulin fraction produce a positive reaction. This subject had a normal sweat chloride level. The sweat chloride levels of the 25 parents are summarized in table II. Only one parent had a chloride.level above $60 \mathrm{mEq} / 1$.

In order to test the genetic implications of the serum factor capable of producing the asynchronous beat, all available members of a family having two children with CFP were studied. The results are shown in figure 3. The whole serum of the father, a brother and both paternal grandparents was found to produce the abnormal ciliary beat. The serum of the mother, maternal aunt and cousin produced the asynchronous beat only when the serum was concentrated and the euglobulin fraction assayed. The sweat chloride levels of all members of this family were measured, and the results in $\mathrm{mEq} / 1$ were: father-37, brother-20, paternal grandfather-56, paternal grandmother -17 , mother-40, paternal aunt-58, uncle-30, maternal aunt 26 and two cousins 25 and 20 respectively.

\section{Discussion}

The present communication stems from the observation that the ciliary rhythm is disorganized when serum from individuals suffering from CFP is added to explants of rabbit tracheal epithelium. It is significant that serum from patients suffering from a variety of other diseases, some having clinical manifestations similar to CFP, did not alter the ciliary motions. This suggested that the effect was unique to serum from patients with GFP.

Since CFP is an inheritable disorder, sera of parents of some of the patients with CFP were examined to determine if the serum factor was present in presumed heterozygotes. In the majority of parents the native serum has little activity, but the concentrated euglobulin fraction (2.5:1 with respect to the concentration in the serum) proved to be active in all 25 parents examined. Among the normal controls examined, only one showed activity in the similarly concentrated euglobulin fraction and no activity could be detected in the remaining 24 . When the euglobulin fraction from normal individuals was concentrated 10 -fold there was no effect on the ciliary rhythm. Commercial pooled human gamma globulin also had no effect. The above results are consistent with the possibility that there is a difference in the levels of this serum factor between homozygotes and the majority of heterozygotes and a qualitative difference between those possessing the mutant gene(s) and the normal population. Although the number of individuals tested is too small to draw conclusions, it is interesting that among the 25 controls with no family history of CFP only one positive result was obtained; approximately $5 \%$, which was the estimated gene frequency in the general population of the United States [5]. Also, the number of heterozygotes found in the family study is compatible with that expected for an autosomal recessive condition. These preliminary results suggest that this technique may be useful for detecting the heterozygous state. Presently only speculation is possible regarding the relation of the serum factor and the mutant gene.

Certain known physical properties of this factor indicate that it is a protein. It is inactivated by heat. It does not pass through a dialysis membrane. It is precipitated as a euglobulin. After fractionation of the serum on Sephadex G-200, the activity is found primarily in the excluded fraction, equivalent to the 19S globulin. Material eluted from the column between the 7S gamma globulin peak and the albumin peak also contains significant activity. A similar distribution is observed when an euglobulin preparation is chromatographed. At the present time, the exact relationship between these two fractions is unknown but it is possible that the smaller molecular weight material is a subunit of the larger component (19S).

The euglobulin precipitate is a relatively clear, gelatinous material suggestive of a mucoprotein. This may be significant in the light of the studies of mucoproteins in cystic fibrosis patients by other investigators. Dische et al. [2] initially observed the presence of an abnormal mucoprotein in the duodenal fluid. Subsequently evidence for distinct mucoproteins has been described in sweat [9], in submaxillary saliva [1], in urine $[8,10]$ and most recently in the feces [6]. The factor found in the urine [ 8 and 10] can be dissociated into subunits, but its solubility characteristics in water and in saline are different from those of the serum factor described here.

At present, no evidence is available regarding the mechanism of the production of the dyskinesis of the ciliary motion in tracheal explants consequent to exposure to the serum of patients with CFP nor is the physiological significance of this finding known. Nasal polyps examined immediately upon removal from a patient with CFP had a normal ciliary rhythm. The ciliary beat of these polyps was affected in the same way as rabbit tracheal explants following the addition of serum from a patient with GFP. 
Efforts are now being directed towards the purification and the characterization of the serum factor with the hope of simplifying the assay and of gaining insight into the nature of the underlying defect.

Summary

A serum factor which causes a dyskinesis of ciliary action in explants of rabbit tracheal epithelium has been found in patients with CFP and their parents. This activity is demonstrable in native serum from homozygotes but the serum of the heterozygote usually required concentration to demonstrate the effect. No activity is found in the sera of normal individuals, even after 10-fold concentration. The activity is associated with the euglobulins, it is nondialysable and heat labile.

\section{References and Notes}

1. Ghernick, W.S. and Barbero, G.J.: Studies on human tracheobronchial and submaxillary secretions in normal and pathophysiological conditions. Ann. N.Y. Acad. Sci. 106: 698 (1963).

2. Drsche, Z.; Dr Sant'Agnese, P.A.; Pallavicini, J.C. and Youlos, J.: Composition of mucoprotein fractions from duodenal fluid of patients with cystic fibrosis of the pancreas and from controls. Pediatrics 24: 74 (1959).

3. Di Sant'Agnese, P. and Powell, G.F.: The exocrine sweat defect in cystic fibrosis of the pancreas (mucoviscidosis). Ann. N.Y. Acad. Sci. 93: 555 (1962).

4. Grbson, L. E. and Cooke, R. E. : A test for concentration of electrolytes in sweat in cystic fibrosis of the pancreas utilizing pilocarpine by contophoresis. Pediatrics 23: 545 (1959).

5. Goodman, H.O. and Reed, S. G.: Heredity of fibrosis of the pancreas; possible mutation rate of the gene. Amer. J. hum. Genet. 4: 59 (1952).

6. Lowe, C.U.; Adler, W. ; Broberger, O.; WALsh, J. and Neter, E.: Mucopolysaccharide from patients with cystic fibrosis of the pancreas. Science 153: 1124 (1966).

7. Mangos, J.A. and McSherry, N.R.: Sodium transport inhibition by the saliva of patients with cystic fibrosis; presented at the 37th Annual Meeting of the Society for Pediatric Research, April 28 (1967).

8. Maxfield, M. and Wolins, W.: A molecular abnormality of urinary mucoprotein in cystic fibrosis of the pancreas. J.clin. Invest. 41: 455 (1962).

9. Pallavicini, J. C.; Gabriel, O.; di Sant'Agnese, P.A. and Buskirk, E.: Isolation and characterization of carbohydrate-protein complexes from human sweat. Ann. N.Y.Acad. Sci. 106: 330 (1963).

10. Talamo, R. G.; Raunio, V.; Gabriel, O.; Pallavicini, J.C.; Halbert, S. and di Sant'Agnese, P.A.: Immunologic and biochemical comparison of urinary glycoproteins in patients with cystic fibrosis of the pancreas and normal controls. J. Pediat. 56: 480 (1964).

11. Presented in part at the 4th International Conference on Cystic Fibrosis of the Pancreas (Mucoviscidosis), Berne/Grindelwald (1966).

12. The authors wish to express their appreciation to Dr. James B.Sidbury for his invaluable advice in the preparation of this paper; to Melvin Hinton for his excellent technical assistance; and to Leonard Hart for the cine photography.

13. Supported in part by National Cystic Fibrosis Research Foundation - AM-06-815, GRU Grant M01-FR-30-0, and USPHS - 1T01 - HDOO-132 Pediatric Training Grant.

14. Spock, A., M.D., Associate Professor, Department of Pediatrics, Duke University Medical Center, Durham, N.C. 27706 (USA). 